\title{
Supply Chain Redesign Employing Advanced Planning Systems
}

\author{
Jim Andersson and Martin Rudberg \\ Jim Andersson, Lawson Sweden, Propellergatan 1, SE-211 19 Malmö, \\ Sweden \\ Martin Rudberg, Department of Management and Engineering, Linköping \\ University, SE-58183 Linköping, Sweden, martin.rudberg@liu.se
}

\begin{abstract}
Higher expectations on supply chain performance force organizations to reinvent themselves in order to cut costs and increase customer service, all to gain competitive advantage. Pursuing the best network of manufacturing, supply and distribution facilities relative the marketplace is therefore on top of many managers "most wanted" list concerning supply chain management. Supply chain planners are thus in need of decision support to be able to establish feasible and sufficient plans. This paper discusses how decision support through advanced planning systems (APS) can assist tactical supply chain planning. A case study is presented showing how APS can act as an enabler in adapting logistics and supply chain principles, as well as reducing costs through streamlining the supply chain. The purpose of this paper is primarily to present findings from a case study regarding supply chain planning with the aid of a master planning APS-module. The case study emphasize that APS in the scope of logistics management have several positive effects on supply chain performance.
\end{abstract}

\section{Keywords}

Supply Chain Management, Supply Chain Planning, Process Industries, Sweden, Production Networks

\section{Introduction}

Many companies that act on both domestic and global markets experience a growing international competition and recognize the need of supply chain efficiency. This need stems from increasing customer demands on high quality products at a low price plus higher expectations on accurate deliveries and customer service 
(Christopher, 2005). Advanced planning systems (APS) can be used as a tool to meet the ever increasing demands on effectiveness that put new pressures on swift and efficient planning and control of the supply chain. APS as a decision support system for production and distribution planning is still a new and fairly unexplored tool (Stadtler and Kilger, 2005; Wu et al, 2000). During the last few years, companies that sell enterprise resource planning (ERP) systems have started developing and implementing APS-modules, which by the aid of sophisticated mathematical algorithms and optimization functionality, supports planning of complex systems such as supply chains (Stadtler, 2005; Wu et al, 2000).

The purpose of this paper is primarily to present findings from a case study regarding supply chain planning with the aid of a master planning APS-module. Unlike traditional ERP systems, APS try to find feasible, near optimal plans across the supply chain as a whole, while potential bottlenecks are considered explicitly (Stadtler and Kilger, 2005). In terms of software, APS means a broad group of software applications developed by various software vendors, such as i2, Manugistics, Oracle, SAP, AspenTech and Lawson. During the last decade, the use of APS for design, integration, and control of supply chain processes have increased. Especially the interest among industrial companies has increased, some have invested in the software, but only few use them in practice on strategic and tactical planning levels. There are also few documented cases showing how standardized APS are used, especially concerning the tactical planning level which is the focus of this paper.

In the following the paper provides a literature review centred on supply chain management and supply chin planning. Thereafter the case study is introduced describing the supply chain redesign, the APS implementation and its results in particular. After an account concerning managerial implications some concluding remarks are also provided.

\section{Supply Chain Management}

Studies on supply chain management often centre on what has been identified as the two main issues concerning the management of value-adding networks; configuration and coordination (Rudberg and West, 2008). This paper addresses both issues, i.e. the configuration of the network and the coordination of the newly configured network. The ever-present questions of, for example, where to allocate production so as to be most responsive and how to maintain low production and transportation costs, become more important when competition increases. Still, the issue of coordination cannot be left aside and must be included when supply chain redesign is considered. In this paper most focus will be put upon coordination of the newly redesigned supply chain with the aid of a master planning APS module.

\subsection{Supply Chain Planning}

Considering the complex environment that most companies have to cope with, most decision-support systems advocates a hierarchical distribution of the decision- 
making processes, where the next upper level coordinates each lower level (Wortmann et al., 1997). Strategic decisions (long horizon and long periods) cannot be based on the same level of detail in the information as is the case for operational decisions (short horizon and short periods). Hence, decisions made at a high hierarchical level are normally based on aggregated information (in terms of product families, factories, etc.) and aggregated time periods. Thereafter these high level decisions form the context for the decision-making processes at lower-level decision centres, where decisions are disaggregated into more detailed information and time periods, but the considered horizon is made shorter. Decisions are thus exploded through the hierarchical structure until the lowest level is reached and detailed decisions are executed.

Planning has in the recent years developed to be supported by optimization and simulation tools, especially concerning "higher" planning levels. Complex trade-off analysis can be calculated with the aid of optimization models and solution heuristics in relatively short computing time (de Kok and Graves, 2003; Chopra and Meindl, 2004). The general trade-off in planning is between service, costs, capital expenditure and working capital (Shapiro, 2001). Cost minimization and profit maximization are the two most common ways to control the solution (Stadtler and Kilger, 2005). Many planning related problems in the supply chain are caused by poor communication and coordination throughout the supply chain. APS has been put forward as one solution to these problems.

APS can be defined and explained through different perspectives but commonly APS is viewed as an extension of ERP. On the other hand, standard APS modules stem from the many in-house developed decision support systems (DSS) that aid planners at various levels in the decision hierarchy (De Kok and Graves, 2003). The literature reports on some successful implementations of DSS in either special supply chain planning situations or optimization models regarding the entire chain. Gupta et al (2002), for example, describe a DSS that helps Pfizer to plan their distribution network. The model is useful in both strategic and operational planning situations. Brown et al (2001) presents a large-scale linear programming optimization model used at Kellogg Company to support production and distribution decision making on both strategic and tactical levels. Arntzen et al (1995) comprehensively describe supply chain optimization at Digital Equipment Corporation.

One way to classify standard APS is by categorizing different modules depending on the length of the planning horizon on the one hand, and the supply chain process that the module supports on the other. Figure 1 categorizes the most common standard APS modules according to these two dimensions (Stadtler, 2005; Meyr et al, 2005), which is a module segmentation also used among software vendors. This study focuses on the tactical level, i.e. multi-site master planning.

\subsection{Supply Chain Master Planning}

Master planning (MP) looks for the most efficient way to fulfil demand forecasts and/or customer orders over a mid-term planning interval (see Figure 1), which often covers a full seasonal cycle. Master planning not only balances demand forecasts with available capacities but also assigns demands (production and distribution 
amounts) to sites in order to avoid bottlenecks (Rohde and Wagner, 2005). Master planning is an important supply chain decision level because to be effective, inputs from throughout the supply chain are required and its results have great impact on the supply chain (Chopra and Meindl, 2004).

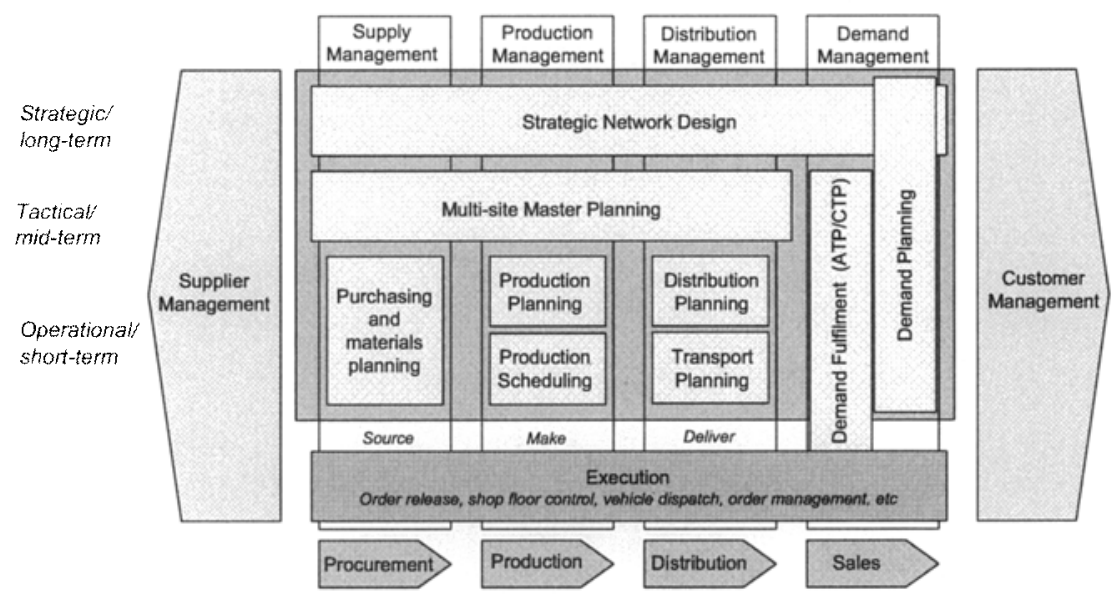

Fig 1:: Typical APS planning structure and categorization of APS modules.

Mid-term planning concerns rough quantities of material supplied, workforce requirements, production quantities and seasonal stock and use of distribution channels. Before operations research (OR) tools like optimization and simulation entered the enterprise planning arena, master planning was often done by traditional infinite MRPII systems, or by simple calculations using spreadsheets without considering capacity limitations (Fleishmann and Meyr, 2003). New OR-related software that conducts master planning using linear programming tries to maximize profit (or minimize costs) while meeting demand (Chopra and Meindl, 2004). To be able to optimize the mid-term supply chain model, production, inventory and distribution must be regarded concurrently. MP uses data on products and material in aggregated product groups. Inputs are demand data and network constraints in terms of a model that defines capacity and dependencies between different processes. The MP results in a common supply chain plan regarding production, distribution, inventory, procurement and materials requirements (Rohde and Wagner, 2005). The case in the following section will describe how supply chain master planning coordinates procurement, production and distribution on the mid-term planning level.

\section{Case: The Farmers Group}

Svenska Lantmännen (The Swedish Farmers Supply and Crop Marketing Association) is one of the leading groups within the grocery and agriculture industry in Sweden. It is a producer cooperative that works together in marketing, 
distribution, sales, processing and supply. Large profit margins are not the goal so much as cost reduction through the entire chain. This is due to that the owners, some 44,000 Swedish farmers, are both suppliers and customers to the central production and distribution function. The Group has some 13,000 employees, markets its products in 19 countries and has a yearly turnover of SEK 32 billion (SEK $100 \approx$ EUR 11). In Sweden, the group is organised in 13 geographically separate areas and supplies its customers with seed, fertilizers and feed among other things, and of course process and sells what the farmers produce. Prior to 2001 the farmers acted in local and regional cooperatives but in 2001, Svenska Lantmännen was founded out of merging these cooperatives. Since then the group has suffered from inefficiency and surplus capacity. Several structural changes and reorganizations have been carried out in order to streamline the business.

The study presented in this paper centers around the seed supply chain which belongs to the division with company-wide logistics responsibility. The product (seed) is, according to Fisher's (1997) definition, functional in its characteristics: low profit margins, low product variety and long lead times for requiring customized products ( 5 to 10 years). Due to the functional characteristics of the product, physical efficiency is the main objective for supply chain design, hence a low cost focus through the entire chain of processes. The demand for seed is highly seasonal, and about $70 \%$ of the volume is sold during a period between December and March. The large volumes and the many suppliers and customers make the business dependent on efficient inventory and distribution management. The planning process is difficult due to the high seasonal fluctuations and the fact that seasonal stock can only be built up in restricted amount.

\subsection{Supply Chain Redesign}

In 2004, a major restructuring of the seed supply chain was undertaken. Two out of six production plants was shut down and two out of four central warehouses were closed. Restructuring the seed supply chain resulted in less capacity in both production and warehouses, and also put higher requirements on distribution activities. Lower capacity and equal requirements on throughput make the planning process harder. The seed supply chain contains 30,000 farmers who act as both suppliers and customers to four production plants and two distribution centres.

Every plant supplies a restricted number of customers within the nearest geographical regions. Only in a few cases the production is differentiated between the plants. The main distribution strategy is to ship finished products directly from the finished products inventory at the plants. This leads to a large number of distribution relations that put pressure on transportation efficiency. To be able to meet the high seasonal demand peaks surplus capacity is needed. Sales forecasts are conducted by the marketing and sales function and are mostly dependent on historical sales data. The access to raw material is in great extent dependent on weather and other factors that are hard to predict. 


\subsection{Implementing an APS}

The restructuring of the supply chain was complemented by changes in the mid-term supply chain master planning in form of a new centralized planning function. Earlier the mid-term planning (including production and distribution) had been carried out locally/regionally with simple spreadsheets. Hence, the new centralized planning function was in need of software decision support in order to find feasible plans for the entire supply chain. The logistics division investigated the use of decision support through APS in a feasibility study in mid 2004. Two months later the APS module Lawson M3 Supply Chain Planner (M3 SCP) was implemented and in use. The tactical planning process and related APS modules are visualized in Figure 2.

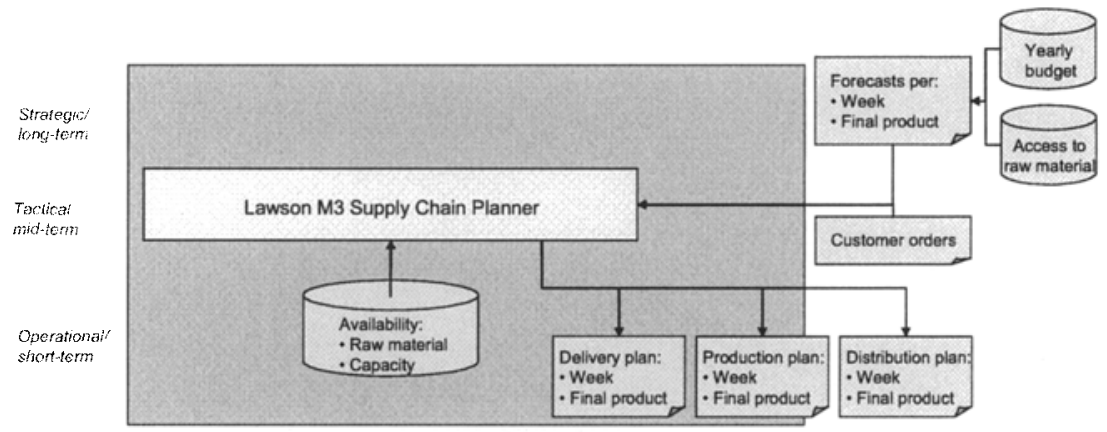

Fig 2. Svenska Lantmännen's tactical planning process and related APS modules

Planning with M3 SCP balances supply and demand for each weekly time bucket during the planning horizon (the remaining season). Forecasts are based on the yearly budgeting process and only updated twice a year. Production and inventory levels are matched with capacity for each period to minimize total supply chain costs, with regard to the four production and two distribution sites. The planning process with M3 SCP is done in an iterative manner where bottlenecks are identified and handled by the planner. Data is extracted from the company's ERP system and used by the M3 SCP module. The solver engine uses linear and mixed-integer programming to solve the planning problem with respect to total cost minimization. Short-term production scheduling as well as planning supply is carried out locally at the plants according to the directions given by the aggregated master plan. Transport planning (routing, loading, etc.) is outsourced to a third party that executes the deliveries within the frames of the distribution plan.

\subsection{Results}

In a study carried out in 2006 (Andersson, 2006), the effects on total costs regarding the seed production and distribution at Svenska Lantmännen was evaluated with respect to the supply chain redesign. At the same time, the flow of goods and the implementation of the APS at the centralized master planning function were 
investigated. The results show that the structural changes and the implementation of the APS have streamlined the production and distribution network regarding the flow of goods. Total costs have decreased by some $13 \%$ on a yearly basis, while at the same time the quantity of sold units has increased. This results in a total reduction of cost by some $15 \%$ per tonne. Furthermore, inventory levels in production facilities and warehouses were reduced by almost $50 \%$, and inventory reductions were realized for raw material, WIP and finished products.

The supply chain planning trade-off have had the following consequences: in general increased production batch sizes, slightly higher transportation costs due to lower fill-rates, decreased production cost and less capital tied up in inventory because of better throughput. The reinvented supply chain planning has reduced the total planning time. Central planning has increased the control of material flows in the chain as well as the cost structure. A higher understanding of the supply chain trade-off makes further development of immediate importance. Optimizing the supply chain has not been the most important objective with the APS implementation. The main focus has been to gain acceptance for central master planning process and to enable communications between functions. In addition to the monetary gains by the restructuring, the new way of planning increased the communication between logistics, manufacturing, marketing and sales functions. The master plans produced by M3 SCP are distributed and discussed between the functions and thereby improved for better fit with actual supply and demand.

\section{Concluding Remarks and Managerial Implications}

To be able to plan and control complex supply chain structures powerful management decision support is needed. Planning has, therefore, in the recent years found a renaissance in the use of optimization and simulation tools. APS uses such optimization and simulation tools, as it considers the supply chain constraints and produces near optimal solutions (Stadtler and Kilger, 2005).

APS can thereby be used as a tool to meet the ever increasing demands on effectiveness that put new pressures on swift and efficient planning and control of the supply chain. APS as a DSS for production and distribution planning is however still a new and fairly unexplored tool. During the last few years, companies that sell ERP systems have started developing and implementing APS-modules, However, only few cases using standardized APS are documented in the literature, and this paper thereby enhances the understanding of APS and its use in practice through a detailed case study. The paper is therefore of value to both academics and practitioners, since it provides an illustration of how state-of-the-art commercial software is applied in a practical setting. The number of documented cases where standard off-the-shelf APS are used in industry is limited, and this paper contributes with case study findings addressing both implementation issues and the day-to-day operational use of the software.

Finally, this research indicates that APS together with a centralized master planning function contributes to the restructuring of the supply chain with more efficient operations as a result. The conclusions that can be drawn from this study is 
that positive effects on throughput and inventory levels, and thus supply chain performance, have been realized with the aid of an APS. However, a prerequisite is that the organization employing the APS is operated effectively, in this case through the restructuring of the supply chain.

\section{References}

Andersson, J. (2006) Avancerade planeringssystem som beslutsstöd vid produktions- och distributionsplanering, Master's thesis, Dept. of Science and Technology, Linköping University, Sweden.

Amtzen, B.C., Brown, G.G., Harrison, T.P. and Trafton, L.L. (1995) Global Supply Chain Management at Digital Equipment Corporation, Interfaces, 25(1), 69-93.

Brown, G., Keegan, J., Vigus, B. and Wood, K. (2001) The Kellogg Company Optimizes Production, Inventory and Distribution, Interfaces, 31(6), 1-15.

Chopra, S. and Meindl, P. (2004) Supply Chain Management - Strategy, Planning and Operation, $2^{\text {nd }}$ edition, Prentice Hall, New Jersey.

Christopher, M. (2005) Logistics and Supply Chain Management: Creating Value-Adding Networks, $3^{\text {rd }}$ edition, Pearson Education Limited, King's Lynn.

De Kok, A.G. and Graves, S.C. (Eds) (2003) Handbook in operations research and management science Vol. II - Supply Chain Management: Design, Coordination and Operation, Elsevier, Amsterdam

Fisher, M.L. (1997) What is the right supply chain for your product? Harvard Business Review, March-April, 105-116.

Fleishmann, B. and Meyr, H. (2003) Planning Hierarchy, Modeling and Advanced Planning Systems In de Kok, A.G. And Graves, S.C. (Eds) Handbook in operations research and management science Vol. 11 - Supply Chain Management: Design, Coordination and Operation, Elsevier, Amsterdam, pp. 457-524.

Gupta, V., Peter, E., Miller, T. and Blyden, K. (2002) Implementing a Distribution-Network Decision-Support System at Pfizer/Warner-Lambert, Interfaces, 32(4), 28-45.

Meyr, H., Wagner, M. and Rohde, J. (2005) Structure of Advanced Planning Systems In Stadtler and Kilger (red) Supply Chain Management and Advanced Planning - Concepts, Models, Software and Case Studies, Springer, Berlin, 109-115.

Rohde, J. and Wagner, M. (2005) Master Planning In Stadtler and Kilger (Eds) Supply Chain Management and Advanced Planning - Concepts, Models, Software and Case Studies, Springer, Berlin, 159-177.

Rudberg, M. and West, M. (2008) "Global Operations Strategy: Coordinating Manufacturing Networks", Omega, 36, 91-106.

Shapiro, J.F. (2001) Modelling the Supply Chain, Thomson, Pacific Grove

Stadtler, H. (2005) Supply chain management and advanced planning - basics, overview and challenges, European Journal of Operations Research, 163, 575-588.

Stadtler, H. and Kilger, C. (Eds) (2005) Supply Chain Management and Advanced Planning Concepts, Models, Software and Case Studies, $3^{\text {rd }}$ edition, Springer, Berlin.

Wortmann, J.C., Muntslag, D.R. and Timmermans, P.J.M. (1997) Customer-driven Manufacturing, Chapman \& Hall, London, UK.

Wu, J., Ulieru, M., Cobzaru, M. and Norrie, D. (2000) Supply Chain Management Systems: state of the art and vision, International Conference on Management of Innovation and Technology (ICMIT). 